\title{
Community-Based Strategy to Prevent Deliberate Self-Harm in Adolescence: An Inquiry to Find Risk Factors at School
}

\author{
Laura Remaschi $^{1{ }^{1,}}$; Cristina Cecchini ${ }^{2} ;$ Patrizia Meringolo $^{1}$ \\ ${ }^{1}$ Department of Education and Psychology, University of Florence, Italy \\ ${ }^{2}$ Department of Information Engineering, University of Florence, Italy \\ *Corresponding author: Laura Remaschi, Department of Education and Psychology, University of Florence, Italy. Tel: +39-3334285339, E-mail: laura.remaschi@gmail.com
}

Received: May 22, 2014; Revised: September 22, 2014; Accepted: September 23, 2014

\begin{abstract}
Background: Self-harm behaviors consist of parasuicidal behaviors, which represent "a deliberate destruction of body tissue, with or without suicidal intent". A theoretical model is the Experiential Avoidance Model. The most frequent risk factors are school distress, poor social integration, poor social and family support, drugs use, sexual abuse, altered sense of life and death, bad relationship with the body and unsolved body mentalization process.

Objectives: The objective of the present study was to perform an analysis of risk factors for self-harm behaviors, to help plan preventive actions.

Patients and Methods: One questionnaire with specific scales was employed for students, whereas three semi-structured interviews were employed for teachers, all on distress perception and self-harm in school.

Results: Data analysis confirms an association between self- cutting and alcohol use, sexual harassments, school dropout, threatening people, incommunicability with family members and negative relationship with the body and suicide attempts, with a clear tendency for males. In the interviews, teachers highlight self-injury as a dysfunctional relationship with the body and observe several risk markers of psychological distress.

Conclusions: The results confirm the available literature data, while noting that self-harming is a preponderantly male behavior. The results also signal the need to create opportunities to instruct teachers to combat the resistances and stereotypes of psychological distress.
\end{abstract}

Keywords:Self-Injurious Behavior; Suicide; Schools; Community Based Participatory Research; Prevention

\section{Background}

\subsection{Deliberate Self-Harm: Definition and Theoreti- cal Model}

Deliberate self-harm (DSH) is a relevant phenomenon that includes several expressions with different import of injury on body, repetitiveness, duration etc., producing anomalies about inclusion or exclusion of behaviors in the classification. In the literature, DSH consists of parasuicidal behaviors, which means "a deliberate destruction of body tissue, with or without suicidal intent" (1), where a definite intention to die discriminates a suicide attempt from the DSH. The most important classifications are "Self-mutilation (SM), DSH, Non suicidal self-injury (NSSI)". Indirect methods as self-starvation, drunken driving, alcohol or drug abuse, smoking (2), as well as more socially acceptable expressions, such as piercing or tattooing, are not considered (3). The set of behaviors consistently changes, depending on the severity of the injury, the repetitiveness and pattern of behaviors. Two prevalent expressions, consisting of slight injuries on the body, are observed: the compulsive type, manifesting with trichotillomania and association with obsessive- compulsive disorder, and the episodic-repetitive type, manifesting as skin cutting and burning, interfering with wound healing, inserting objects under the skin, hitting the body with objects (4). Pattison and Kahan explain that self-injury occurs within a short time frame and people are fully aware of the effects on their body (5). The low lethality of DSH separates it from conscious suicide attempts, because it appears to be a maladaptive coping strategy, unlike a real purpose to die. Several previous research trials stated that the suicidal intent is difficult to recognize, because people often conceal it; therefore, a clear discrimination between the two phenomena is impossible (5). The high comorbidity between DSH and suicidal behaviors (6), as well as the increased suicide risk for people with DSH history, support this matter. Furthermore, in Italy, an official non-suicidal DSH index is not yet present. This is a limitation for the studies, since references and data are only international. The Experiential Avoidance Model (7) provides a model merging the previous theoretical models. The model asserts that DSH (without suicidal intent) is a negatively reinforced strategy to reduce or end an unwanted emotional arousal; this consists of any behavior suitable to avoid eliciting stressful internal and external experiences (e.g. thoughts, memo- 
ries, somatic sensations). Multiple strategies can be used: thought suppression, drug and alcohol use, avoidance of feared settings and objects. Although it is a maladaptive coping strategy, it is suitable to escape unwanted feelings, and to act as a strong negative reinforcement.

\subsection{Risk Factors and Prevention in Deliberate Self- Harm}

Klonsky, (8) found seven functions for DSH. Two functions are more frequent: the affect-regulation function is a strategy to control negative feelings and restore wellbeing; the self-punishment function is a strategy where anger is addressed against oneself. The precipitating risk factors of DSH and suicide are school dropout, poor family and social support, early puberty, impulse control disorder, use, abuse or addiction to substances, breach of law, living in marginal risk districts, belonging to deviant groups, psychiatric parents (9). Along with psycho-pathological factors, it is included a problematic integration, detachment experiences, unworked breakdown and frustration, unclear sexual orientation, social exclusion and withdrawal. Besides intrapsychic factors, it is important to analyze adolescent sense of life and death, looking at suicides as a possible answer to conflicts. Another important factor in adolescence is the body mentalization. The adolescent uses body changes to build a new mental representation. The body becomes the symbolic expression of internal and relational conflicts, as well as a means to reach both social and gender identity. The failure of the body mentalization process could be the reason of the aggressive behaviors against the self. Specific interventions for DSH are still missing, and primary prevention of DSH is rare. The first step could be to realize actions for protection and risk factors survey (10), besides focusing on life skills improvement, by educational programs, and increasing coping strategies (11), emotional expression (3) and stress management $(12,13)$. School could be a preventive context, where planning specific programs can be easily done. Because of this, our study involved three secondary schools in the area of Florence. The purpose was to perform and analysis of risk factors for DSH, to plan preventive actions.

\section{Objectives}

The research analyses young adults' well-being, in particular the relationship with the body, social and family support and life approach. The aim is to analyze risk factors of DSH and to promote awareness about the behavior.

\section{Patients and Methods}

\subsection{Participants}

A total of 313 students, 18 - 22 years old (mean age $=20.8$ years), of which $63 \%$ were male and $37 \%$ were female. The sampling is snowball and voluntary, but questionnaires compilation was held exclusively in the fifth section classes, as participants should be adults. Teachers of the three different secondary schools in Florence (from where the students were selected) also participated in the study by filling special interviews.

\subsection{Measures and Data Analysis}

The close ended questionnaire was divided into two sections: a first section concerned everyday life topics (free time activities and fun, family communication and relationships, risk behaviors, externalizing/internalizing behaviors, stressful events) and a second section with specific scales: the BAT: Body Attitudes Test (no Italian version is yet validated. Ten out of 20 items were translated; discarded items were not suitable to males); the Italian validation of MSPSS: Multidimensional Scale of Perceived Social Support; the MAST: Multi-Attitude Suicide Tendency scale (only 14 items were picked from the Italian validation); the Italian validation of PWB: Psychological Well-being Scales by Ryff (14). The questionnaire was given to students during school time. To avoid bias, the research was described as a study on young adults' life styles. Results were discussed with students and teachers. To investigate the topic from the teachers' point of view, a semi-structured interview was submitted to health education teachers. The interview focused on the following topics: professional history, distress perception in school (particularly for DSH) cases histories, recommended actions, criticalities and resources in the school and area. A quantitative descriptive analysis was conducted and the associations between variables were examined by one-way ANOVA and Pearson's correlation. In particular, ANOVA analyzed different answers on the cutting item among groups (i.e. school, sex, family communication and stressful events). If possible, by the Bonferroni Index, a second analysis was conducted. Correlations were analyzed among the cutting item and risk behaviors (i.e. "Have you ever had unprotected sex?"), internalizing behaviors (i.e. "Have you ever eaten as much as you should?") and externalizing behaviors (i.e. "Have you ever threatened other people?"). Correlations among cutting item and scales and subscales were examined. The contents of the interview were analyzed with the Atlas.ti software (ATLAS.ti Scientific Software Development GmbH, Berlin, Germany).

\section{Results}

\subsection{Questionnaires}

Participants were recruited from the Florentine area, both urban and rural. They spend their free-time surfing the internet, chatting, watching TV and listening to the music on their own, which is the only recurring activity they also enjoy a lot. Everyday activities are more lonely and of average fun, while they show more pleasure in occasional and more cohesive pastimes, such as doing 
sport, going to the disco and concerts, being with boyfriend/girlfriend and going to the cinema. Some of them belong to associations (44\%): half of them to a sport association, the others to cultural, health, religious, social associations. Through ANOVA, we observe an association between failing a school year and self-cutting (see Table 1); this agrees with the literature, where school distress is an important risk factor (15).

Of them, 5.4\% acknowledge engaging intentional selfcutting at least sometimes, which supports referential literature (16-18), and $64.7 \%$ of them are male. This contrasts literature, which only attributes self-harm behavior to females $(3,15,17-26)$. Nevertheless, threatening other people is correlated with cutting item, which appears to be explained by the highest incidence of boys revealing DSH. The differences among school types on cutting are not shown. The research finds no association between social support and cutting; enhancing the topic is suggested, considering the wide range the literature gives to social support as a protective factor (27-29). The research observes an association between family incommunicability and DSH, supporting the evidence in literature (30) (See Table 2). The presence of tattoos and piercings was examined, although no significant association was found with DSH. Concerning substances and alcohol use, a statistical association between getting drunk and cutting was found, partially validating the literature, which attests alcohol and the Bonferroni Index.

Substances use/abuse, along with smoking cigarettes, are strong risk factors for DSH $(15,31,32)$. Sexual harassments in the past 3 years associate with cutting (See Table 3), supporting the hypothesis which considers it the main risk factor for DSH (32-36).

\begin{tabular}{lcccc}
\hline \multicolumn{1}{l}{ Table 1. ANOVA for Failure } & & \\
\hline & & & \multicolumn{2}{c}{ Self-Cutting } \\
\cline { 2 - 4 } & Subjects & Mean \pm SD & Fisher F-value & Statistical Significance Between The Groups \\
\hline Failure & $68^{\mathrm{a}}$ & $1.10 \pm 0.306$ & 4.025 & \\
Yes & 245 & $1.04 \pm 0.013$ & & \\
No & 313 & $1.05 \pm 0.227$ & & \\
Total & & & \\
\hline
\end{tabular}

$\mathrm{a}_{\mathrm{P}}<0.05$ represents the statistical significance.

Table 2. Bonferroni Index on Family Relationship

\begin{tabular}{lcc}
\hline Variable & & Self-Cutting \\
\hline Family Relationship & Difference Among Means & Significance Among the Groups \\
\hline Close opinions & & 0.036 \\
Different opinions, good relationship & -0.103 & 0.119 \\
Silence & & 0.516 \\
Different opinions, good relationship & -0.036 & 0.05 \\
Close opinions & $-0.139^{\mathrm{a}}$ & \\
Silence & & 0.119 \\
Silence & 0.103 & 0.05 \\
Close opinions & $0.139^{\mathrm{a}}$ \\
\hline Different opinions, good relationship & & \\
\hline
\end{tabular}

${ }^{\mathrm{a}} \mathrm{P}<0.05$ represents the statistical significance.

Table 3. ANOVA for Sexual Harassments

\begin{tabular}{lcccc}
\hline Variable & \multicolumn{2}{c}{ Self-Cutting } \\
\cline { 2 - 4 } & Subjects & Mean \pm SD & Fisher Fvalue & Significance Between the Groups \\
\hline Sexual harassments & 6 & $1.33 \pm 0.516$ & 9.494 \\
Yes & 307 & $1.05 \pm 0.216$ & \\
No & 313 & $1.05 \pm 0.227$ & \\
Total & & & \\
\hline
\end{tabular}

$\mathrm{a}_{\mathrm{P}}<0.01$ represents the statistical significance. 
Remaschi L et al.

Other risk behaviors, such as dangerous driving and gambling, or internalizing behaviors, are not related with Self-cutting. Nevertheless, Self-cutting-related variables, such as getting drunk and threatening other people, are associated with other risk behaviors. This situation could be of considerable proportions, according to the hypothesis that DSH could represent the presence of additional risk behaviors (15). Among stressful and traumatic events, except sexual harassments, no association with cutting was found. Several data where self-harm is a nonfunctional strategy to cope with stress, were not confirmed $(7,8)$. The BAT scale was significantly related to cutting, confirming the difficult relationship with the body to be a risk factor and the need for preventive actions on this topic. An association between the Life Repulsion subscale, MAST scale, and Self-cutting is found (see Figure 1), which appears to support literature asserting self-harm and suicide attempts are related $(4,6,10,15,26$, 28, 37-41).

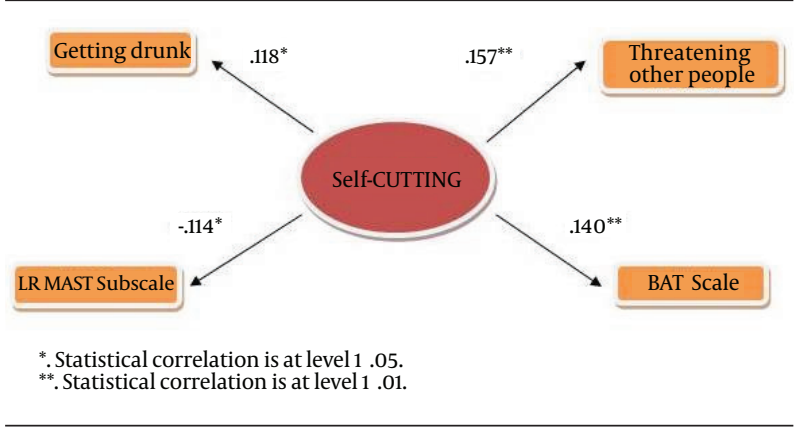

Figure 1. Quantitative Variables Related to Cutting

\subsection{Interviews to Teachers}

What appears in the interviews is consistent with the questionnaire data. Teachers highlight that DSH is a dysfunctional relationship with the body. Eating disorders and substance abuse are considered self-injurious, too. They run into this type of distress: "She showed me, under her gloves, she had signs indeed." Their role is critical to express the problem and to manage it further by the school, by the family and, then, by the services. They highlight distress markers: discipline difficulties ("Clear provocative attitudes: the teacher comes in, she had unsuitable attitudes"), rules respect difficulties, important social introversion, substance use and abuse and family troubles. The role of the teacher is critical, first in noticing these signs "I perceived distress, I saw her standing on her own all the time, she never employed her body, she was not joyful, she showed me the cuts." then establishing a trust relationship in order to talk frankly with students. "We try carefully to make them feel we are close to them, it can be a moment where we start talking." They state that it is a teacher's duty to lead students to psychological consultant and to family: "At least, let's look at them: how can you act as if nothing has happened? Let the parents come, let's talk to them," or they say "Is there any problem, how are you? Is something wrong?". Then I immediately say there is a service, because I absolutely give no kind of advice, my work is noticing." They also observe peers support and their involvement is important "The class is usually completely welcoming towards distressed people." Greater criticalities are connected with bureaucratic features, such as the teachers' turnover, and the needed fulfillments to start an intervention. Communication difficulties with both teachers and students and family are predominant. A marked taboo on open distress expression is present and the determined prejudice in Italian culture about psychic distress. "They are still suspicious to go to the listening desk, because going to the psychologist is "insane." "I did not want him to respond, such as 'Mrs, what? Do you think I need it?" Besides, it is not clear what they can do. "As we are still afraid of making a mistake and getting in trouble, sometimes, in doubt, we keep back rather than take a step forward." Teachers gave valuable advice: besides already started interventions, such as the psychological consultant and the health education classes, they consider the clarification and formalization of the class coordinator survey and handling very important, and they highlight that a referential action protocol is recommended. According to these teachers, open attitude, attention to distress signs recognition and relational and communicative abilities are basic features to start dealing with these problems, to involve the family and to start a supporting extracurricular networking.

\subsection{Data Return to Students and Teachers}

To improve life quality in the school community, results were discussed with participating students and teachers. To rouse a feedback, students expressed their opinions on nameless post-its. The comments reproduce current teenagers' behaviors, and the study usefulness was acknowledged. Someone identified in the questionnaire a way to better understand one and the others. Other participants observed an incongruity among the results and the personal perception of the phenomenon, which is higher. Students were advised to focus on the relationship with the body.

\section{Discussion}

This study confirms existent data in the literature, as in the case of the association between Self-cutting and alcohol use, and between Self-cutting and sexual harassments. A male predominance in self-injurious behaviors was found. An association between self-cutting and the relation with the body was confirmed. Self-injury and the MAST scale were related, highlighting a relation with suicide attempts and suggesting an analysis of the risk factors mediating these behaviors. The present research also emphasizes the role of the school, by finding associations between self-cutting and school dropout. School 
is confirmed to be an appropriated environment to start preventive actions. This is consistent with teachers' assertions about school, as an educational community, where they actively have to operate. However, a psychological counselor must be present, to handle situations with increased risks. Peers, family and local services involvement are basic actions to be taken. Moreover, suggesting the creation of opportunities to instruct teachers with appropriate tools may also prove fundamental. This could be useful to fight resistances due to negative stereotypes of psychological distress and stigmatization. Finally, this research builds a link between pure survey and psychological and educational action. A cooperation among researchers, teachers and psychologists is still present, to start further comparison opportunities on observed topics, involving families.

\section{Acknowledgements}

Authors acknowledge head masters, teachers and students of the high schools involved in the project.

\section{Authors' Contributions}

Laura Remaschi wrote the project, found participants, realized the interview and performed qualitative analysis, and wrote the research report. Cristina Cecchini administrated questionnaires, realized quantitative analysis. Patrizia Meringolo supervised the entire project.

\section{References}

1. Favazza AR. Why patients mutilate themselves. Hosp Community Psychiatry. 1989;40(2):137-45.

2. Lundh LG, Karim J, Quilisch E. Deliberate self-harm in 15-yearold adolescents: a pilot study with a modified version of the Deliberate Self-Harm Inventory. Scand J Psychol. 2007;48(1):33-41.

3. Suyemoto KL. The functions of self-mutilation. Clin Psychol Rev. 1998;18(5):531-54.

4. Hawton K, Zahl D, Weatherall R. Suicide following deliberate self-harm: long-term follow-up of patients who presented to a general hospital. BrJ Psychiatry. 2003;182:537-42.

5. Pattison EM, Kahan J. The deliberate self-harm syndrome. Am J Psychiatry. 1983;140(7):867-72.

6. Cooper J, Kapur N, Webb R, Lawlor M, Guthrie E, Mackway-Jones $\mathrm{K}$, et al. Suicide after deliberate self-harm: a 4-year cohort study. Am J Psychiatry. 2005;162(2):297-303.

7. Chapman AL, Gratz KL, Brown MZ. Solving the puzzle of deliberate self-harm: the experiential avoidance model. Behav Res Ther 2006;44(3):371-94.

8. Klonsky ED. The functions of deliberate self-injury: a review of the evidence. Clin Psychol Rev. 2007;27(2):226-39.

9. Schwartz KA, Pyle SA, Dowd MD, Sheehan K. Attitudes and beliefs of adolescents and parents regarding adolescent suicide. Pediatrics. 2010;125(2):221-7.

10. Gould MS, Kramer RA. Youth suicide prevention. Suicide Life Threat Behav. 2001;31(s1):6-31.

11. Brent DA. The aftercare of adolescents with deliberate selfharm. J Child Psychol Psychiatry. 1997;38(3):277-86.

12. Lloyd-Richardson EE, Perrine N, Dierker L, Kelley ML. Characteristics and functions of non-suicidal self-injury in a community sample of adolescents. Psychol Med. 2007;37(8):1183-92.

13. Hawton K. Sex and suicide. Gender differences in suicidal behaviour. Br J Psychiatry. 2000;177:484-5.

14. Ryff CD. Happiness is everything, or is it? Explorations on the meaning of psychological well-being. Journal of Personality and
Social Psychology. 1989;57(6):1069-81.

15. Brunner R, Parzer P, Haffner J, Steen R, Roos J, Klett M, et al. Prevalence and psychological correlates of occasional and repetitive deliberate self-harm in adolescents. Arch Pediatr Adolesc Med. 2007;161(7):641-9.

16. De Leo D, Heller TS. Who are the kids who self-harm? An Australian self-report school survey. Med J Aust. 2004;181(3):140-4.

17. Patton GC, Harris R, Carlin JB, Hibbert ME, Coffey C, Schwartz M et al. Adolescent suicidal behaviours: a population-based study of risk. Psychol Med.1997;27(3):715-24.

18. Hawton K, Rodham K, Evans E, Weatherall R. Deliberate self harm in adolescents: self report survey in schools in England. BMJ. 2002;325(7374):1207-11.

19. Madge N, Hewitt A, Hawton K, de Wilde EJ, Corcoran P, Fekete S, et al. Deliberate self-harm within an international community sample of young people: comparative findings from the Child \& Adolescent Self-harm in Europe (CASE) Study. J Child Psychol Psychiatry. 2008;49(6):667-77.

20. Evans E, Hawton K, Rodham K, Deeks J. The prevalence of suicidal phenomena in adolescents: a systematic review of population-based studies. Suicide Life Threat Behav. 2005;35(3):239-50.

21. Gratz KL. Measurement of deliberate self-harm: Preliminary data on the Deliberate Self-Harm Inventory. J Psychopathol Behav Assess. 2001;23(4):253-63.

22. Briere J, Gil E. Self-mutilation in clinical and general population samples: prevalence, correlates, and functions. Am J Orthopsychiatry. 1998;68(4):609-20.

23. Muehlenkamp JJ, Gutierrez PM. An investigation of differences between self-injurious behavior and suicide attempts in a sample of adolescents. Suicide Life Threat Behav. 2004;34(1):12-23.

24. Fliege H, Kocalevent RD, Walter OB, Beck S, Gratz KL, Gutierrez $\mathrm{PM}$, et al. Three assessment tools for deliberate self-harm and suicide behavior: evaluation and psychopathological correlates. J Psychosom Res. 2006;61(1):113-21.

25. Klonsky ED, Oltmanns TF, Turkheimer E. Deliberate self-harm in a nonclinical population: prevalence and psychological correlates. Am J Psychiatry. 2003;160(8):1501-8.

26. Whitlock J, Knox KL. The relationship between self-injurious behavior and suicide in a young adult population. Arch Pediatr Adolesc Med. 2007;161(7):634-40.

27. Nock MK, Prinstein MJ. Contextual features and behavioral functions of self-mutilation among adolescents. J Abnorm Psychol. 2005;114(1):140-6.

28. Prinstein MJ, Boergers J, Vernberg EM. Overt and relational aggression in adolescents: social-psychological adjustment of aggressors and victims. J Clin Child Psychol. 2001;30(4):479-91.

29. Storch EA, Masia-Warner C. The relationship of peer victimization to social anxiety and loneliness in adolescent females. $J$ Adolesc. 2004;27(3):351-62.

30. Yates TM, Tracy AJ, Luthar SS. Nonsuicidal self-injury among "privileged" youths: longitudinal and cross-sectional approaches to developmental process. J Consult Clin Psychol. 2008;76(1):52-62.

31. Harned MS, Najavits LM, Weiss RD. Self-harm and suicidal behavior in women with comorbid PTSD and substance dependence. Am J Addict. 2006;15(5):392-5.

32. Langbehn DR, Pfohl B. Clinical correlates of self-mutilation among psychiatric inpatients. Ann Clin Psychiatry. 1993;5(1):4551.

33. Favazza AR, Rosenthal RJ. Diagnostic issues in self-mutilation. Hosp Community Psychiatry. 1993;44(2):134-40.

34. Ghaziuddin M, Tsai L, Naylor M, Ghaziuddin N. Mood disorder in a group of self-cutting adolescents. Acta Paedopsychiatr. 1992;55(2):103-5.

35. Favaro A, Santonastaso P, Monteleone P, Bellodi L, Mauri M, Rotondo A, et al. Self-injurious behavior and attempted suicide in purging bulimia nervosa: associations with psychiatric comorbidity. J Affect Disord. 2008;105(1-3):285-9.

36. Murray CD, Macdonald S, Fox J. Body satisfaction, eating disorders and suicide ideation in an Internet sample of self-harmers reporting and not reporting childhood sexual abuse. Psychol Health Med. 2008;13(1):29-42.

37. Owens D, Horrocks J, House A. Fatal and non-fatal repetition of 
self-harm. Systematic review. BrJ Psychiatry. 2002;181:193-9.

38. Safer DJ. Self-reported suicide attempts by adolescents. Ann Clin Psychiatry. 1997;9(4):263-9.

39. Harriss L, Hawton K. Suicidal intent in deliberate self-harm and the risk of suicide: the predictive power of the Suicide Intent
Scale. J Affect Disord. 2005;86(2-3):225-33.

40. Hawton K, Fagg J. Suicide, and other causes of death, following attempted suicide. Br J Psychiatry. 1988;152:359-66.

41. Foster T, Gillespie K, McClelland R. Mental disorders and suicide in Northern Ireland. BrJ Psychiatry. 1997;170:447-52. 